\title{
Chemotherapy for 70-Year-Old Women with Breast Cancer in Germany: A Survey by the German Breast Group
}

\section{Chemotherapie für eine 70-jährige Mammakarzinompatientin in Deutschland: Eine Umfrage der German Breast Group}

Authors

Affiliations
J. Barinoff ${ }^{1}$, A. Traut ${ }^{1}$, D. Bauerschlag ${ }^{2}$, J. Bischoff ${ }^{3}$, D. Herr ${ }^{4}$, K. Lübbe ${ }^{5}$, H.-J. Lück ${ }^{6}$, N. Maass ${ }^{2}$, C. Mundhenke ${ }^{7}$, M. Schmidt ${ }^{8}$, K. Schwedler ${ }^{9}$, M. Thill ${ }^{10}$, J. Steffen ${ }^{11}$, S. Loibl ${ }^{11}$, G. von Minckwitz ${ }^{11}$

The affiliations are listed at the end of the article
Key words

- breast carcinoma

- breast malignancy

- metastasis

Schlüsselwörter

- Mammakarzinom

- Mammamalignom

- Metastasierung

\section{received $\quad 30.10 .2012$ \\ revised 16.4.2013 \\ accepted 16.4.2013}

\section{Bibliography}

Dol http://dx.doi.org/

10.1055/s-0032-1328612

Geburtsh Frauenheilk 2013; 73 :

433-439 @ Georg Thieme

Verlag KG Stuttgart · New York . ISSN 0016-5751

\section{Correspondence}

Dr. med. Jana Barinoff

Kliniken Essen Mitte

Gynäkologie und

Gynäkologische Onkologie

Henricistraße 92

45136 Essen

barinoff.jana@googlemail.com

\section{Abstract \\ $\nabla$}

Aim: Around half of all women in Germany with breast cancer are older than 65 and approximately one third of them is older than 70 years of age. In theory, the preferred therapeutic management of women with breast cancer aged 65 and above corresponds to that formulated for younger patients and complies with the S3 Guidelines and the therapy recommendations formulated by AGO. To study the current therapies used to treat women with breast cancer aged 70 and above in Germany, a survey of the clinics of the German Breast Group (GBG) was done.

Method: An online survey was carried out with requests sent to 599 physicians registered as principal investigators in the database of the GBG. The 12-item questionnaire was used to investigate the systematic therapeutic management of 70-yearold patients in different settings. The indication for chemotherapy was taken as a given.

Results: In a neoadjuvant setting, $62 \%$ of physicians opted for anthracycline and taxane-based therapy as did $56.6 \%$ of physicians in an adjuvant setting. One third of physicians preferred a taxane-based therapy with the anti-angiogenesis inhibitor bevacizumab as first-line therapy for primary metastatic cancer and after anthracyclinebased therapy. Capecitabine (around 30\%) and navelbine (around 20\%) were proposed as second-line neoadjuvant and adjuvant therapies after prior anthracycline- and taxane-based therapy.

Conclusion: The chemotherapy regimen prescribed for women with breast cancer aged 70 and above in Germany appears to be relatively standardised and corresponds to the recommendations given in the S3 Guidelines and by the AGO Breast Committee.

\section{Zusammenfassung \\ $\nabla$}

Ziel: Ca. die Hälfte der Patientinnen mit Mammakarzinom ist über 65 Jahre alt und ca. ein Drittel ist älter als 70 Jahre. Formell entsprechen die therapeutischen Präferenzen für die über 65-jährigen Brustkrebspatientinnen den Konzepten für jüngere Patientinnen und sind konform mit den Konzepten in der S3-Leitlinie sowie den von der AGO formulierten Therapieempfehlungen. Um das aktuelle Therapieverhalten in Deutschland für über 70-jährige Patientinnen mit Mammakarzinom zu erfassen, wurde eine Umfrage bei Prüfzentren der German Breast Group (GBG) durchgeführt.

Methode: Es wurde eine Online-Umfrage unter 599 studienverantwortlichen Ärzten durchgeführt, die in der Datenbank der GBG als Prüfarzt/ärztin registriert sind. Mit dem 12-Item-Fragebogen wurde die systemische Therapieeinsätze bei einer 70-jährigen Patientin in verschiedenen Settings untersucht. Die Indikation für eine Chemotherapie wurde als gegeben definiert.

Ergebnis: 62\% der Ärzte in der Neoadjuvanz und 56,6\% in der Adjuvanz entschieden sich für eine anthrazyklin- und taxanhaltige Therapie. In der primär metastasierenden Situation sowohl in der First-Line-Therapie nach einer anthrazyklinhaltigen Therapie wurde von einem Drittel der Befragten eine taxanhaltige Therapie mit Antiangiogenese-Hemmer Bevacizumab präferiert. Bestand der Status nach anthrazyklin- und taxanhaltiger Therapie in der Neo-/Adjuvanz, so wurden solche Substanzen als Capecitabin (ca. 30\%) und Navelbine (ca. 20\%) eingesetzt.

Fazit: Das Regime einer Chemotherapie bei einer 70-Jährigen und älteren Patientin in Deutschland zeigt eine relativ einheitliche Ausrichtung und entspricht den Empfehlungen der S3-Leitlinien und AGO Mamma. 


\section{Introduction}

\section{$\nabla$}

Every year, approximately 72000 new invasive and non invasive breast carcinomas are diagnosed in Germany. Women aged 65 to 69 are in first place, with a total of 409.6 new diagnoses per 100000 in 2007-2008 (age-specific disease rate). The group aged $70-74$ comes in second, with 333.8 new diagnoses per 100000 , closely followed by the group of women aged 75-79 with 325.3 new diagnoses per 100000 . Women aged $80-85$ had an age-specific disease rate of 348.6/100000, and women aged 85 and above a rate of $361.5 / 100000$ per year [1]. This means that just over half of all breast cancer patients are 65 or above and around one third are older than 70 years of age $[2,3]$.

The number of women aged 65 and above in Germany is expected to double in the next 20 years $(\mathrm{NCCN})$ as the generation of baby boomers becomes older (in Germany, persons born between 1955 and 1965 are defined by statisticians as part of the baby-boom generation). This is important, because women over 70 are currently under-represented in the adjuvant clinical trials carried out to date, meaning that therapy decisions are often taken without being based on sufficient reliable data [4-7]. It is important to note that certain factors may also be significant in addition to purely chronological age. Such factors include physiological and functional reserve, co-morbidities, cognitive function, the availability of social support and individual life expectancy [5, 7]. For example, $17 \%$ of the group aged between 65 and 74 had 6 co-morbidities. For the group of women over 75 this figure had increased to $27 \%$.

The preferred therapeutic management of women with breast cancer aged over 65 corresponds to the concepts formulated for younger patients and complies with the concepts outlined in the S3 Guidelines [8] and the therapy recommendations formulated by AGO [9]. However, as was recently reported by Hancke et al., only some of the elderly patients in Germany receive therapy which complies with the guidelines [10]. Another recent study by Sautter-Bihl et al. reviewed the literature on "elderly patients and breast cancer" and came to the conclusion that "female patients with a life expectancy of more than 5 years and not very extensive co-morbidities should receive adjuvant chemotherapy, trastuzumab and radiation in accordance with current standards, while frail elderly women should receive reduced or no adjuvant standard therapy" [11].

To investigate the current therapeutic management in Germany of women with breast cancer over 70 years of age, a survey of the clinics of the German Breast Group (GBG) was carried out.

\section{Method}

$\nabla$

An online survey was done of 599 physicians registered in the database of the GBG as principal investigators. The physicians were contacted once by e-mail; there was no recall system.

The main focus when the case-related 12-item questionnaire was developed was on the clinical relevance of individual questions ( Table 1). The questionnaire consisted of 11 multiple-choice questions and one open-ended question where only one answer was permitted. The questions related to the therapeutic management selected for a patient aged between 70 and 80 with an ECOG performance status of 1 , certain stable pre-existing conditions which were managed with medication and did not constitute a contraindication to specific cytostatic drugs. For the purposes of the study, it was assumed that chemotherapy in differ-
Table 1 Questionnaire and characteristics of participants.

\begin{tabular}{|c|c|c|}
\hline Questions & Number & Percentage \\
\hline \multicolumn{3}{|l|}{ Do you work in: } \\
\hline A tertiary care centre for oncology & 66 & 42.0 \\
\hline A general hospital & 22 & 14.0 \\
\hline A doctor's surgery & 40 & 25.5 \\
\hline A university clinic & 21 & 13.4 \\
\hline Unknown & 8 & 5.1 \\
\hline \multicolumn{3}{|l|}{ In which capacity? } \\
\hline Resident physician & 3 & 1.9 \\
\hline Chief physician/head of department & 63 & 40.1 \\
\hline Specialist & 26 & 16.6 \\
\hline Senior physician & 52 & 33.1 \\
\hline Unknown & 13 & 8.3 \\
\hline \multicolumn{3}{|c|}{ You have completed your medical training as, or are training to be: } \\
\hline A gynaecologist & 120 & 76.4 \\
\hline $\begin{array}{l}\text { A medical oncologist } \\
\text { also trained as an internist }\end{array}$ & 24 & 15.3 \\
\hline Unknown & 13 & 8.3 \\
\hline \multicolumn{3}{|c|}{$\begin{array}{l}\text { How many cases with breast cancer (primary diagnosis) } \\
\text { did you treat last year in your surgery/clinic? }\end{array}$} \\
\hline $0-30$ & 1 & 0.6 \\
\hline $30-60$ & 15 & 9.6 \\
\hline $60-100$ & 21 & 13.4 \\
\hline $100-200$ & 59 & 37.6 \\
\hline $200-300$ & 30 & 19.1 \\
\hline $300-400$ & 13 & 8.3 \\
\hline$>500$ & 9 & 5.7 \\
\hline \multicolumn{3}{|c|}{$\begin{array}{l}\text { How many cases of metastatic breast cancer (new patients) } \\
\text { were treated last year for the first time in your surgery/clinic? }\end{array}$} \\
\hline $0-10$ & 5 & 3.2 \\
\hline $10-20$ & 45 & 28.7 \\
\hline $30-40$ & 46 & 29.3 \\
\hline $40-50$ & 19 & 12.1 \\
\hline $50-100$ & 20 & 12.7 \\
\hline $100-200$ & 10 & 6.4 \\
\hline
\end{tabular}

ent settings (neoadjuvant, adjuvant, palliative) was indicated; the indication for chemotherapy itself was not an issue.

The time for response was set at 4 weeks; analysis was done after the data had been anonymised. No comparison between participants and nonparticipants was done. Descriptive analysis was done using IBM SPSS Statistics 20 [12] and Excel 2010 [13]; the results were shown using vertical bar charts and pie charts.

\section{Results}

In all, 159 physicians (26.5\%) out of a total of 599 physicians registered as principal investigators responded; 137 (22.9\%) answered all questions, a further 22 (3.7\%) only answered some of the questions. The characteristics of participating physicians are given in 0 Table 1.

Analysis of the responses to the question of how many cases with primary breast cancer were treated annually in the physician's institution showed that most facilities (37.6\%) treated between 100 and 200 cases of primary breast cancer every year, $19.1 \%$ of investigated institutions treated $200-300$ cases annually, $13.4 \%$ of institutions treated $60-100$ breast cancers per year, $8.3 \%$ of clinics were breast centres with between 300-400 primary cases annually, and $5.7 \%$ of institutions treated more than 500 primary cases over a period of 12 months. With regard to new patients with metastatic breast cancer, one third of participating physi- 


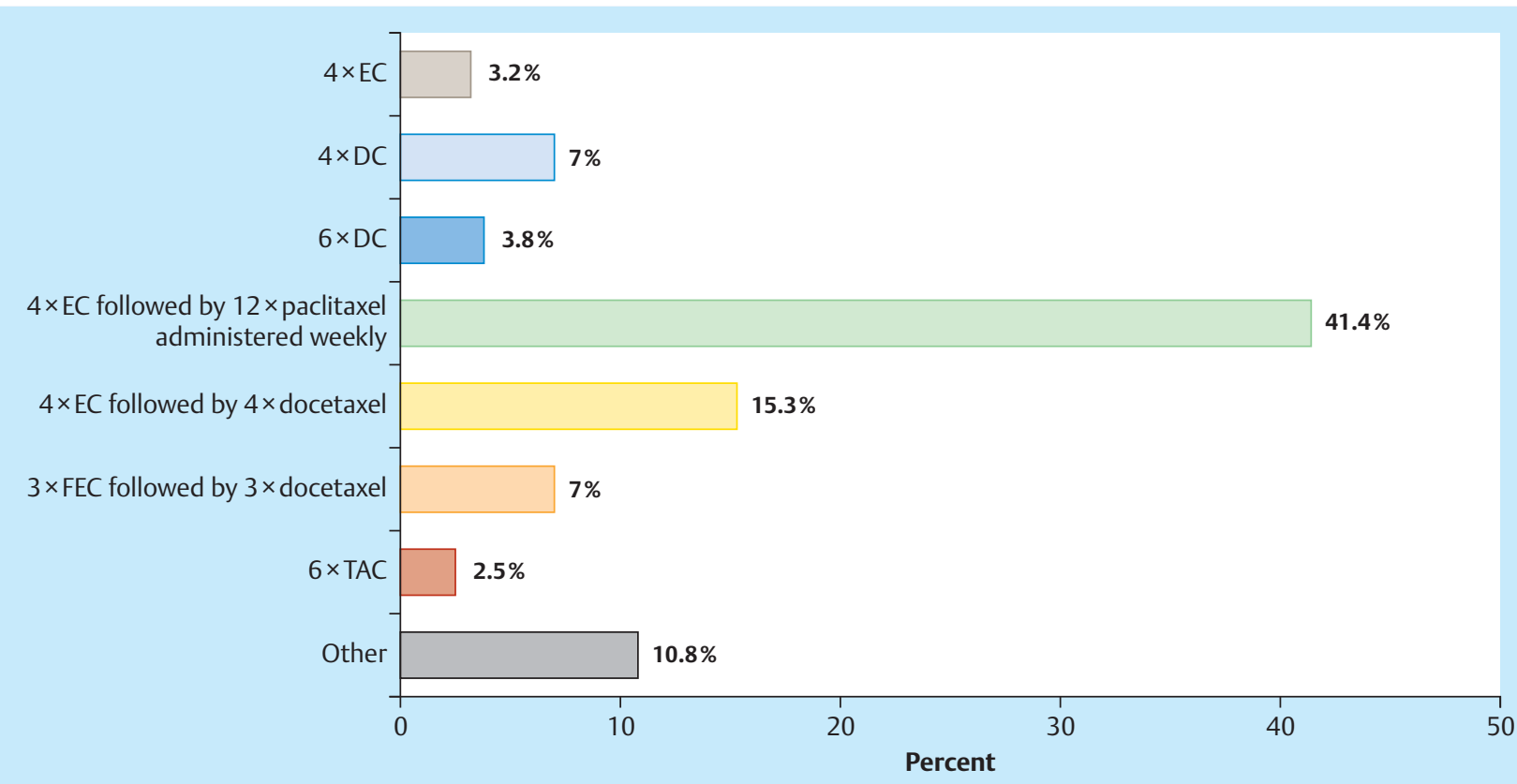

Fig. 1 Question: "Which neoadjuvant regimen are you most likely to use in this situation?” EC - epirubicin, cyclophosphamide; DC - docetaxel, cyclo- phosphamide; FEC - fluorouracil, epirubicin, cyclophosphamide; TAC - docetaxel, adriamycin, cyclophosphamide. cians respectively reported seeing $30-40$ and $10-20$ patients per year (29.3 and $28.7 \%$, respectively). $12.7 \%$ of respondents diagnosed metastatic breast cancer in around 50-100 patients annually and $6.4 \%$ of participants treated $100-200$ patients with a diagnosis of metastatic breast cancer every year ( Table 1 ).

If neoadjuvant chemotherapy was indicated in a patient (this presupposed that chemotherapy was indicated in this patient based on tumour metrics, lymph node status, negative HR status or positive HER2/neu status), just under $40 \%$ of all respondents stated their preference for sequential anthracycline-/taxanebased therapy ( $4 \times$ EC followed by $12 \times$ paclitaxel weekly) fest. To treat such cases $15 \%$ of physicians would prescribe a regimen of $4 \times$ EC followed by $4 \times$ docetaxel, and $7 \%$ would opt for $3 \times$ FEC followed by $3 \times$ docetaxel. Another $7 \%$ of physicians would recommend $4 \times$ docetaxel/cyclophosphamide (DC). Around $11 \%$ of physicians chose the category "other" ( $\bullet$ Fig. 1 ).

In the event that adjuvant chemotherapy was prescribed in the same patient, the most commonly chosen combination (39.5\%) was $4 \times$ EC followed by $12 \times$ paclitaxel weekly. Only $2.5 \%$ of physicians opted for a regimen consisting of $4 \times$ EC followed by $4 \times$ docetaxel, while $14.6 \%$ of physicians recommended $3 \times$ FEC followed by $3 \times$ docetaxel, $9.6 \%$ would prescribe $4 \times$ DC, and only $3.2 \%$ of physicians opted for $4 \times \mathrm{EC}$ ( $\odot$ Fig. 2 ).

In the next question the clinical situation was altered such that it reflected a situation whereby the patient presented with primary metastatic disease. Once again, it was assumed that chemotherapy was indicated. $36.3 \%$ of physicians recommended primary taxane monochemotherapy and just under 30\% would recommend one of the specified monochemotherapies in combination with bevacizumab (participants were given a choice between the following chemotherapeutic substances: taxane, anthracyclines, capecitabine, vinorelbine) ( $\bullet$ Fig. 3 ).

In the event that metastasis was first found in the same patient after a disease-free interval of 2.5 years and chemotherapy was considered necessary, $42.7 \%$ of respondents opted for a taxanebased monotherapy if the patient had previously been treated with anthracyclines in a neoadjuvant/adjuvant setting ( $\bullet$ Fig. 4). In contrast, $2.5 \%$ of physicians preferred a taxane-based approach if an anthracycline and taxane-based therapy had been previously administered in a non-metastatic situation; capecitabine and vinorelbine therapy were the substances of choice used for first-line therapy (29.3 and $19.1 \%$, respectively). In both groups the percentage of respondents opting for a combination with bevacizumab was 30.6 and $25.5 \%$, respectively ( Fig. 5).

Finally, all participants were asked whether they would be interested in participating in clinical studies of elderly patients. 54.1, 81.5 and $58.6 \%$ of physicians, respectively, would be interested in participating in a neoadjuvant, adjuvant or palliative study ( Table 2). 31 colleagues also proposed various study designs: $30 \%$ proposed a mono-regimen with nab-paclitaxel, liposomal doxorubicin, eribulin, capecitabine or vinorelbine in every setting; a chemotherapy-free concept with trastuzumab and endo-

Table 2 Open questions about trials portfolio.

\begin{tabular}{|c|c|c|}
\hline & Number & Percentage \\
\hline \multicolumn{3}{|c|}{$\begin{array}{l}\text { Would you be interested in participating in a study on chemotherapy } \\
\text { for elderly female patients in a neoadjuvant setting? }\end{array}$} \\
\hline Not ticked & 72 & 45.9 \\
\hline Yes, I would be interested & 85 & 54.1 \\
\hline \multicolumn{3}{|c|}{$\begin{array}{l}\text { Would you be interested in participating in a study on chemotherapy } \\
\text { for elderly female patients in an adjuvant setting? }\end{array}$} \\
\hline Not ticked & 29 & 18.5 \\
\hline Yes, I would be interested & 128 & 81.5 \\
\hline \multicolumn{3}{|c|}{$\begin{array}{l}\text { Would you be interested in participating in a study on chemotherapy } \\
\text { for elderly female patients in a metastatic setting? }\end{array}$} \\
\hline Not ticked & 65 & 41.4 \\
\hline Yes, I would be interested & 92 & 58.6 \\
\hline
\end{tabular}




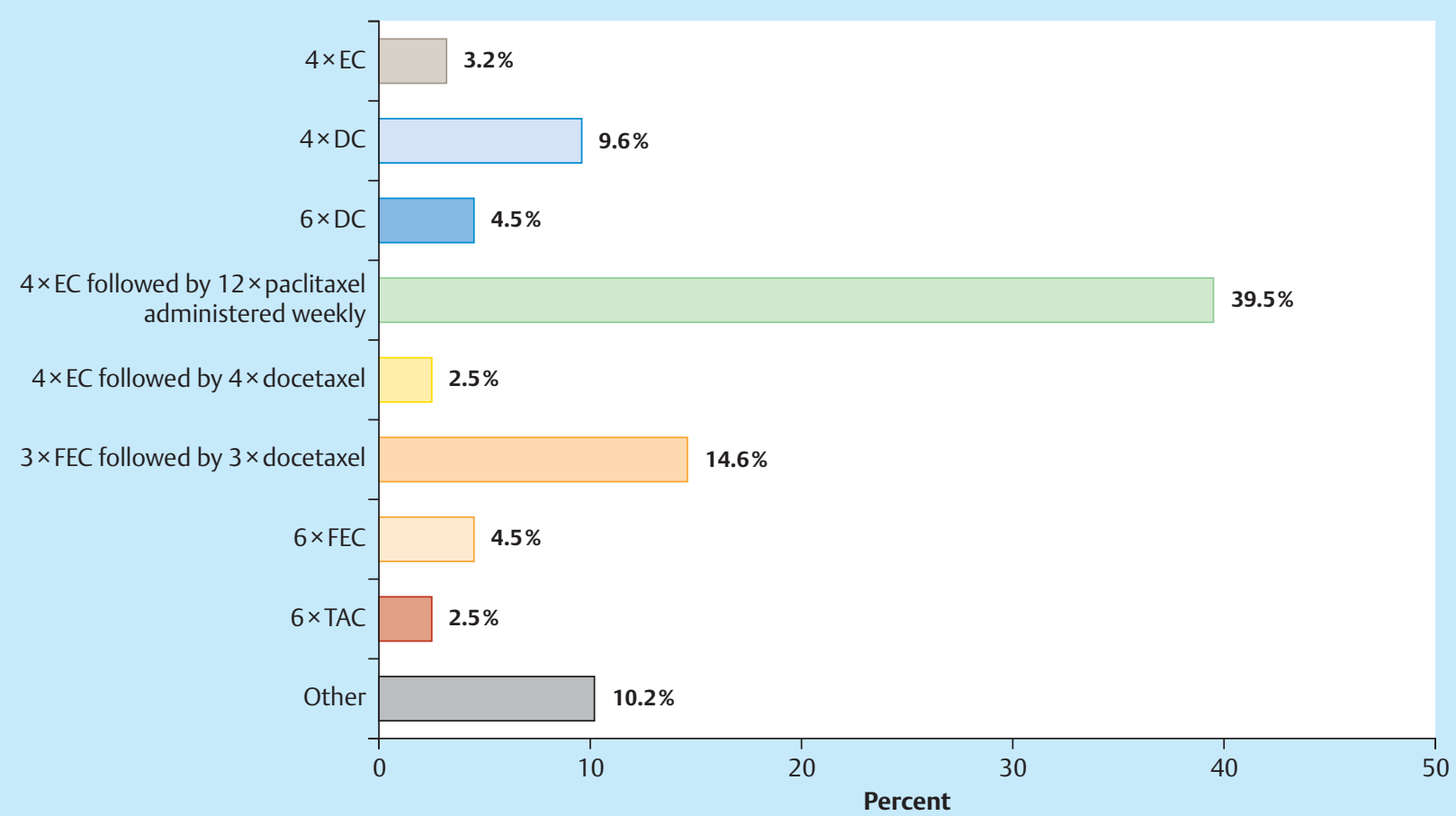

Fig. 2 Question: "Imagine you are treating the same patient but this time adjuvant chemotherapy is indicated. Which regimen would you be most likely to prescribe in this situation?"

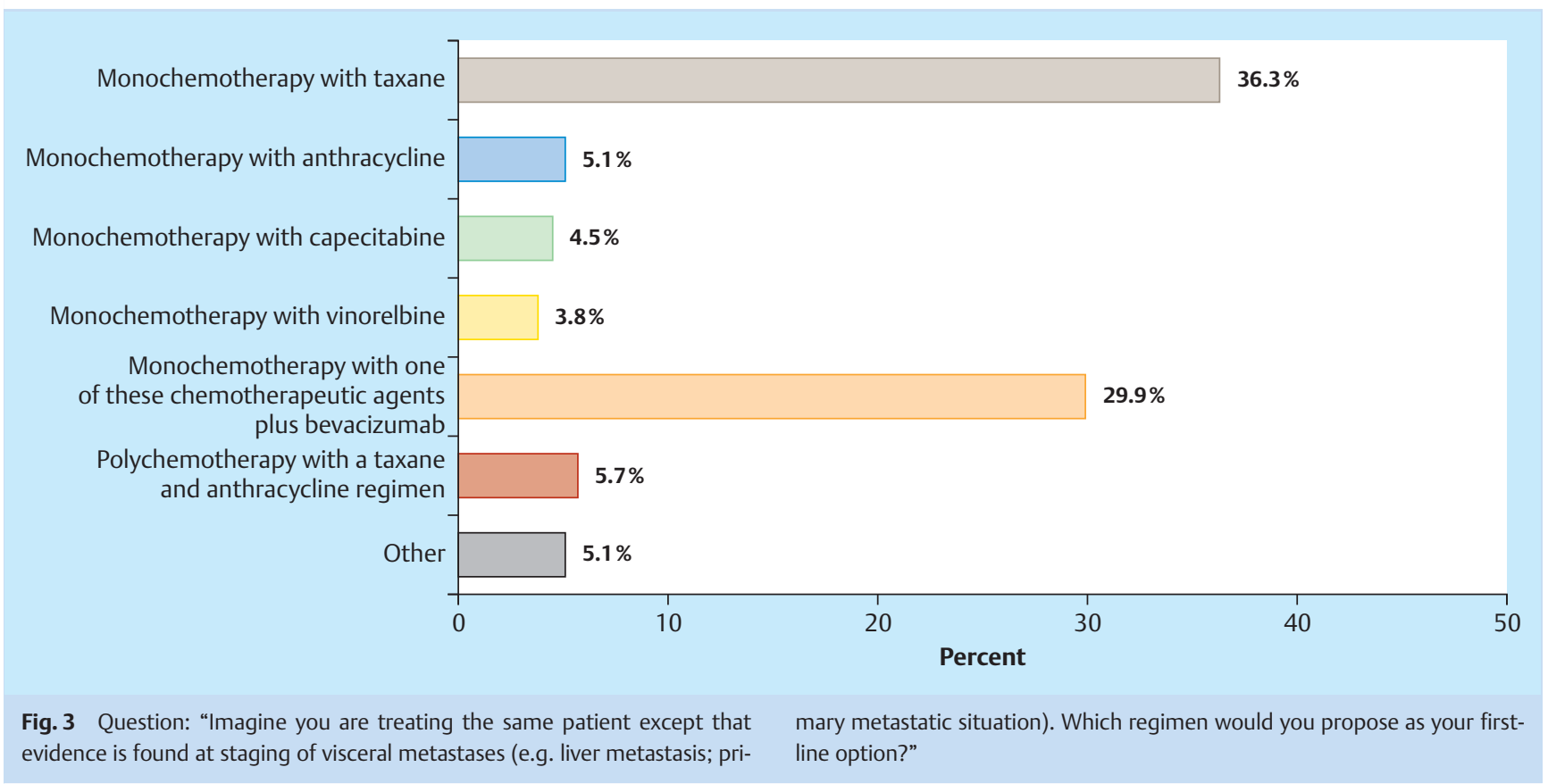

crine therapy was preferred for HER2/neu-positive patients. The second most commonly proposed variant was doublet therapy with 4-6 $\times$ docetaxel/cyclophosphamide vs. $4 \times$ EC followed by $12 \times$ paclitaxel. The idea of comparing monochemotherapy with polychemotherapy in a (neo)adjuvant setting was discussed by around 25\%; $10 \%$ also mentioned a combination with the angiogenesis inhibitor bevacizumab. Overall, the proposed study designs were tailored with a view to encouraging compliance and took account of co-morbidities and quality of life.

\section{Discussion}

The aim of this study was to obtain a representative overview of chemotherapy management concepts in Germany in 2012 for female patients aged 70-80 with an ECOG 1 performance status. Participants in the survey consisted of physicians registered as principal investigators of studies by the GBG; thus it can be assumed that this amounts to a pre-selection of participants as these physicians would have a greater clinical and scientific in- 

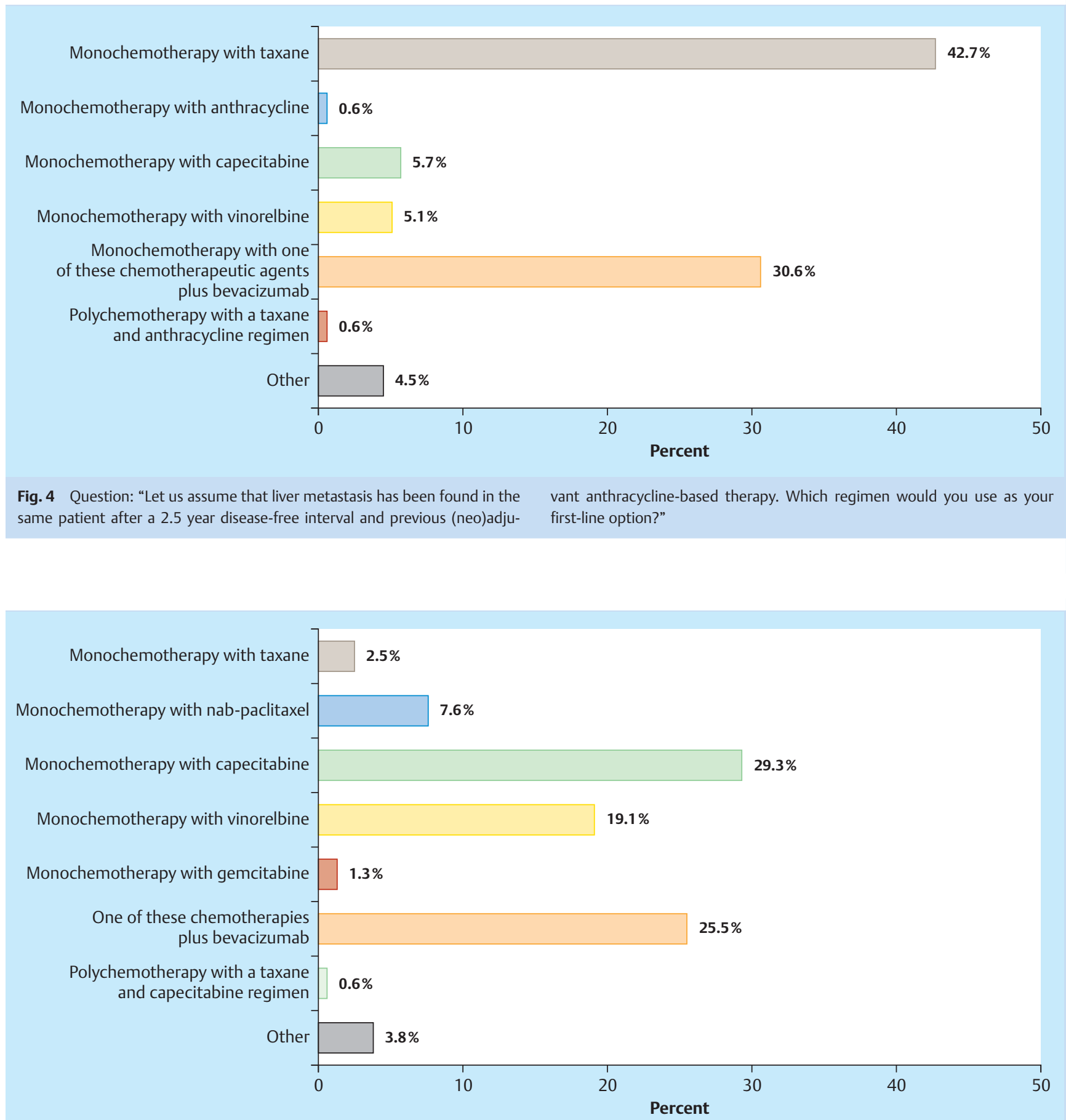

Fig. 5 Question: "Let us assume the same patient had previously been treated with anthracycline and taxane in a (neo)adjuvant setting. Which regimen would you use as your first-line option?"

terest in management strategies for these elderly patients. The rate of return was satisfactory, with around $25 \%$ of physicians responding; however the return rate was lower than in other countries $[14,15]$. More than $40 \%$ of respondents worked at tertiary care centres for oncology and $13 \%$ at university clinics. Surprisingly, fully one quarter of respondents were not hospital-based but had their own practice, making them the second largest group of respondents. The largest group (40\%) consisted of chief physicians and heads of departments; this demonstrates that the heads of departments are usually responsible for monitoring and managing studies and trials, and underscores their importance in this context. Whether the distribution of medical specialties two thirds of the physicians in this study were gynaecologists and $15 \%$ were medical oncologists who had also trained as internists - corresponds to the reality outside the confines of the GBG is doubtful.

Most breast centres in this survey treated between 100 and 200 cases with primary cancer very year. Around $14 \%$ of institutions treated between 300 and 500 cases with breast cancer over a period of 12 months. $60 \%$ of physicians treated between 10 and 40 
new patients with metastatic breast cancer per year. Around 6\% of respondents reported that they treated between 100-200 new patients with metastasis over a 12 month period. It would be possible to use this information in the context of the existing discussion on poor recruitment into palliative studies and select the most suitable study centres accordingly.

As regards the choice of chemotherapies for women without metastasis the results were as follows: anthracycline/taxane-based therapy was found to play a central role in the therapy of women aged $70-80$ years, both in a neoadjuvant and an adjuvant setting, despite the fact that the current guidelines are based on data obtained from female patients under 65.

The choice of therapies in a palliative setting was a clear indication of the participating physicians' preferences: taxane-based monotherapy was the therapy of choice, both for patients with primary metastatic breast cancer and for women with secondary metastatic carcinoma. The combination of chemotherapy plus bevacizumab reported in one third of the responses shows that this substance has also found a place in the management of elderly patients. If the patient had had previous treatment with anthracyclines and taxanes, a majority of physicians recommended a monotherapy with capecitabine or vinorelbine. It was clear that a combination therapy played no role as first-line option for the management of women with metastatic breast cancer aged 70 or above.

When asked about possible study designs, most physicians reported that they would recommend monotherapy with its reduced side-effects in a (neo)adjuvant setting, even though the current standard consists of a sequential regimen of three substances.

The issue of the "undertreatment" of elderly patients was and is controversial. In 2013, Malik et al. published a study in the USA in which they found no difference in 5-year (local and distant) disease-free survival between "undertreated" patients and patients treated according to conventional criteria [16]. Despite all the limitations of this study (it was a retrospective, single-centre analysis; the data acquisition period was 1978-2012) the authors questioned the role of therapy carried out in accordance with conventional guidelines in this cohort of patients.

A number of prospective randomised studies were able to show that older patients also benefited from anthracycline or taxanebased chemotherapy with regard to survival [17-19]. However, the inclusion criteria in these studies were "unfavourable tumour biology" and "hormone receptor negativity" or "positive lymph node status". Loibl et al. carried out a pooled analysis of 4 (neo)adjuvant studies and showed for this cohort that age can have an impact on the feasibility of therapy and on side-effects [20]. Further important information obtained in this study was that toxicity was less pronounced with sequential regimens compared to a combined regimen.

The recommendations for the therapeutic management of elderly patients made by the International Society of Geriatric Oncology (SIOG) and the European Society of Breast Cancer Specialists (EUSOMA) emphasise that the decision as to whether chemotherapy is indicated should not be based on age alone; it was recommended that patient examination must also include a standardised geriatric assessment [21]. The review article by Sautter-Bihl et al. cited above stated that, outside of the guidelines, due to the limited data on the toxicity of adjuvant regimens in elderly patients, management could consist of an anthracycline monotherapy or alternately 4 cycles respectively of docetaxel/ doxorubicin or doxorubicin/cyclophosphamide [11]; however, this regimen was not recommended in our current GBG survey. Nevertheless it is indisputable that therapeutic management of this group of patients must be flexible in view of the co-morbidities generally present in this cohort and indications for therapy must therefore be assessed very carefully. The limited data on toxicity and chemotherapeutic management for this group of patients can only remedied by designing and carrying out further clinical studies; the ICE-II study of the GBG could serve as a good example in this context [22]. The current therapeutic recommendations of the AGO Breast Committee suggest that such patients should preferably receive chemotherapy as part of a study (LOE: 2a/c, AGO recommendation +) [9].

In summary it can be stated that the chemotherapeutic management in Germany of female patients with breast cancer aged 70 and above appears to be relatively standardised and complies with the recommendations of the S3 Guidelines [23] and made by the AGO Breast Committee [9] as well as those of SIOG and EUSOMA [21].

\section{Conflict of Interest \\ $\nabla$}

None.

\section{Affiliations}

${ }^{1}$ Gynäkologie und Gynäkologische Onkologie, Kliniken Essen Mitte, Essen

2 Frauenklinik für Gynäkologie und Geburtshilfe, Universitätsklinikum Aachen, Aachen

${ }^{3}$ Universitätsfrauenklinik, Universitätsklinikum Magdeburg A.ö. R, Magdeburg

${ }^{4}$ Klinik für Gynäkologie und Gynäkologische Onkologie, Dr-Horst-SchmidtKliniken, Wiesbaden

${ }^{5}$ Klinik für Gynäkologie und Geburtshilfe, Diakoniekrankenhaus Henriettenstiftung, Hannover

${ }^{6}$ Gynäkologisch-Onkologische Schwerpunktpraxis, Hannover

${ }^{7}$ Frauenklinik, Universitätsklinikum Schleswig-Holstein, Kiel

${ }^{8}$ Klinik und Poliklinik für Geburtshilfe und Frauenkrankheiten, Universitätsmedizin Mainz, Mainz

${ }_{9}$ Neue Frauenklinik, Luzerner Kantonsspital, Luzern, Switzerland

10 Klinik für Gynäkologie und Geburtshilfe, Agaplesion Markus Krankenhaus, Frankfurt am Main

11 German Breast Group, Neu Isenburg

\section{References}

1 Robert Koch-Institut; Gesellschaft für epidemiologische Krebsregister in Deutschland e.V., eds. Krebs in Deutschland 2007/2008. Häufigkeit und Trends. 8th revised ed. Berlin: Robert Koch-Institut; 2012; www.rki. de/krebs; last access: 5.10 .2012

2 Jahrbuch Statistisches Bundesamt für die Bundesrepublik Deutschland 2008. http://www.destatis.de; last access: 5.10 .2012

3 Robert Koch-Institut; Gesellschaft für epidemiologische Krebsregister in Deutschland e.V., eds. Krebs in Deutschland 2005/2006. Häufigkeiten und Trends. 7th revised ed. Berlin: Robert Koch-Institut; 2010; www. rki.de/krebs; last access: 5.10.2012

4 Gennari R, Audisio RA. Breast cancer in elderly women. Optimizing the treatment. Breast Cancer Res Treat 2008; 110: 199-209

5 Bernardi D, Errante D, Galligioni $E$ et al. Treatment of breast cancer in older women. Oncologica 2008; 47: 187-198

6 Reed MWR, Wyld L, Ellisy P et al.; on behalf of the ACTION and ESTEeM Trial Management Groups. Breast cancer in older women: trials and tribulations. Clin Oncol 2009; 21: 99-102

7 Wildiers H, Kunkler I, Biganzoli L et al. Management of breast cancer in elderly individuals: recommendations of the International Society of Geriatric Oncology. Lancet 2007; 8: 1101-1115

8 www.dggg.de/startseite/nachrichten/s3-leitlinie-mammakarzinom/; last access: 12.10 .2012

9 www.ago-online.de/de/fuer-mediziner/leitlinien/mamma/; last access: 12.10 .2012

10 Hancke K, Denkinger MD, König J et al. Standard treatment of female patients with breast cancer decreases substantially for women aged 70 years and older: a German clinical cohort study. Ann Oncol 2010; 21: 748-753 
11 Sautter-Biehl ML, Souchon R, Gerber B. Adjuvante Therapie des Mammakarzinoms bei Patientinnen über 65 Jahre. DÄ 2011; 108: 365-371

12 www-01.ibm.com/software/de/stats20/; last access: 5.10.2012

13 microsoft-excel-2010.softonic.de/; last access: 5.10.2012

14 Grava-Gubins I, Scott S. Effects of various methodologic strategies: survey response rates among Canadian physicians and physicians-intraining. Can Fam Physician 2008; 54: 1424-1430

15 Thorpe C, Ryan B, McLean SL et al. How to obtain excellent response rates when surveying physicians. Fam Pract 2009; 26: 65-68

16 Malik MK, Tartter PI, Belfer I. Undertreated breast cancer in the elderly. JCE 2013; Article ID 893104; Epub 2013 Jan 10

17 Crivellari D, Bonetti M, Castiglione-Gertsch $M$ et al. Burdens and benefits of adjuvant cyclophosphamide, methotrexate, and fluorouracil and tamoxifen for elderly patients with breast cancer: The International Breast Cancer Study Group Trial VII. J Clin Oncol 2000; 18: 1412-1422

18 Reimer T, Nitz U, Potenberg J. Capecitabine as adjuvant treatment in elderly patients with early breast cancer - an interim safety analysis of the ICE studies. Breast Cancer Res Treat 2006; 100 (Suppl. 1): S112
19 Jones S, Holmes FA, O'Shaughnessy J. Docetaxel with cyclophosphamide is associated with an overall survivial benefit compared with doxorubicin and cyclophosphamide: 7-year follow-up of US oncology research trial 9735. J Clin Oncol 2009; 27: 1177-1183

20 Loibl S, von Minckwitz G, Harbeck N et al. Clinical feasibility of (neo)adjuvant taxane-based chemotherapy in older patients: analysis of $>4,500$ patients from four German randomized breast cancer trials. Breast Cancer Res 2008; 10: R77

21 Biganzoli L, Wildiers H, Oakman C et al. Management of elderly patients with breast cancer: updated recommendations of the International Society of Geriatric Oncology (SIOG) and European Society of Breast Cancer Specialists (EUSOMA). Lancet Oncol 2012; 13: e148-e160

22 www.germanbreastgroup.de/studien.html; last access: 10.12 .2012

23 Interdisziplinäre S3-Leitlinie für die Diagnostik, Therapie und Nachsorge des Mammakarzinoms. Version 3.0, Aktualisierung 2012. www. senologie.org/publikationen/leitlinien/; last access: 10.12.2012

Deutschsprachige Zusatzinformationen online abrufbar unter: www.thieme-connect.de/ejournals/toc/gebfra. 